\title{
A Proteção dos Direitos Humanos LGBT e os Princípios Consagrados Contra a Discriminação Atentatória
}

\author{
Dirceu Pereira Siqueira \\ Pós-doutorado em Direito pela Faculdade de Direito da \\ Universidade de Coimbra (Portugal), doutor e mestre em \\ Direito Constitucional pela Instituição Toledo de Ensino - \\ ITE/Bauru -, especialista em Direito Civil e Processual pelo \\ Centro Universitário de Rio Preto, pesquisador bolsista - \\ Modalidade Produtividade em Pesquisa para Doutor (PPD) \\ do Instituto Cesumar de Ciência, Tecnologia e Inovação \\ (Iceti), professor permanente do Programa de Mestrado \\ em Direito do Centro Universitário Cesumar (UniCesumar) \\ e nos cursos de Graduação em Direito da Universidade de \\ Araraquara (Uniara), do Centro Universitário Unifafibe (Uni- \\ fafibe) e do Centro Universitário da Fundação Educacional \\ de Barretos (Unifeb), advogado. dpsiqueira@uol.com.br
}

\section{Robson Aparecido Machado}

Mestre em Direito pelo Centro Universitário de Maringá UniCesumar, advogado. robsonbarretos@adv.oabsp.org.br

\section{Resumo}

Este artigo tem por objetivo refletir sobre a importância e necessidade de uma proteção estatal para as pessoas LGBTs, uma vez que pertencem a uma minoria social e sexual e têm seus direitos humanos reconhecidos pela ONU, bem como a Constituição Federal prevê o princípio da igualdade no caput do artigo 5e e, ainda, dispõe que "a lei punirá qualquer discriminação atentatória dos direitos e liberdades fundamentais", no inciso XLI, do artigo 5․ Uma das formas de garantia dessa igualdade são as políticas públicas para o combate das discriminações homofóbicas, possibilitando a participação destas minorias no processo político e acesso à educação e emprego.

Palavras-chave: Direitos humanos. Proteção internacional. Constituição Federal. Discriminação. Homofobia. Minorias sexuais. 


\title{
The Protection of LGBT Human Rights and the Consecrated Principles Against Attacking Discrimination
}

\begin{abstract}
This article aims to reflect on the importance and necessity of state protection for LGBT people, since they belong to a social and sexual minority and have their human rights recognized by the UN, as well as the Federal Constitution foresees the principle of equality in the caput of article 5, and also states that "the law shall punish any discrimination that violates fundamental rights and freedoms", in clause XLI of article 5. One of the forms of guaranteeing this equality is the public policies to combat homophobic discrimination, allowing the participation of these minorities in the political process and access to education and employment.
\end{abstract}

Keywords: Human rights. International protection. Federal Constitution. Discrimination. Homophobia. Sexual minorities.

Recebido em: 10/4/2017

Aceito em: 28/6/2017

\section{Sumário}

1 Introdução. 2 0s Direitos Humanos e a Proteção Internacional Contra a Discriminação Atentatória. 3 Distinção entre Direitos Humanos, Direitos Fundamentais e Direitos da Personalidade. 4 Princípios Constitucionais Contra a Discriminação Atentatória. 5 Discriminação e Preconceito Homofóbico. 6 A Homofobia Como Violação dos Direitos e Liberdades Fundamentais. 7 Minorias Sexuais e os Grupos Vulneráveis. 8 Considerações Finais. 9 Referências. 


\section{INTRODUÇÃO}

No século 20, em razão das atrocidades cometidas aos seres humanos durante o holocausto nazista na Segunda Guerra Mundial, ocasião em que foram assassinados milhares de homossexuais, judeus, ciganos, pessoas com deficiência e demais minorias, os Estados criaram a Organização das Nações Unidas (ONU), em 1945, como uma verdadeira liga para a paz mundial.

Em 1948, a Declaração Universal dos Direitos do Homem trouxe uma visão contemporânea da universalidade e indivisibilidade dos direitos humanos. Assim, o requisito para ser titular desses direitos é a condição de ser pessoa, de ser humano, sendo garantidos esses direitos para todos os indivíduos, sem distinção de raça, cor, orientação sexual, religião, língua, nacionalidade ou qualquer outra forma. Os direitos humanos visam à proteção das pessoas contra ações que interferem em suas liberdades ou violem sua dignidade humana.

A ONU não havia tratado sobre o tema da orientação sexual e da identidade de gênero até o julgamento de um caso concreto de homossexualidade na Austrália, em 1994. Como as leis australianas criminalizam a prática homossexual, o Comitê Internacional de Direitos Civis e Políticos, vinculado ao Conselho de Direitos Humanos da ONU, declarou que as leis que violam os direitos LGBTs violam as leis de Direitos Humanos.

Nessa linha, a ONU editou, em 2011, uma Resolução no Conselho de Direitos Humanos, a qual foi apresentada conjuntamente pelo Brasil e pela África do Sul, denominada "Direitos Humanos, orientação sexual e identidade de gênero”. Essa foi a primeira Resolução de defesa dos direitos das pessoas LGBTs a ser aprovada pela ONU. Entre as reivindicações mais importantes está a solicitação de um estudo sobre leis discriminatórias e atos praticados com motivação homofóbica. 
Destaca-se que o conceito de discriminação está estritamente vinculado aos objetivos fundamentais da Constituição Federal, quais sejam: "promover o bem de todos, sem preconceitos de origem, raça, sexo, cor, idade e quaisquer outras formas de discriminação”, disposto no artigo $3^{\circ}$, inciso IV.

O Brasil adotou como princípio basilar e um dos fundamentos da República Federativa do Brasil, nos termos do artigo $1^{\circ}$, inciso III, da Constituição Federal, a Dignidade da Pessoa Humana. Ainda, outros princípios repudiam a discriminação atentatória e o preconceito sobre a orientação sexual e a identidade de gênero: o princípio da não discriminação e o princípio da igualdade.

Uma das formas de garantia dessa igualdade são as ações afirmativas, ou seja, políticas públicas que têm por objetivo combater discriminações de todo tipo, aumentando a participação das minorias no processo político, com acesso à educação e emprego, corrigindo, assim, toda forma de desigualdade.

Nesse sentido, o objetivo geral deste trabalho é refletir sobre a necessidade de uma proteção estatal para a classe de pessoas pertencentes à minoria social e sexual denominada "LGBT", posto que a Constituição Federal, em seu artigo $5^{\circ}$, caput, consagrou o princípio da igualdade e, ainda, no inciso XLI, dispõe que "a lei punirá qualquer discriminação atentatória dos direitos e liberdades fundamentais”.

A metodologia utilizada foi a dedutiva, pois se partiu da interpretação dos princípios constitucionais da dignidade da pessoa humana, da igualdade, da vedação de discriminação, bem como da violação dos direitos da personalidade. Além disso, empregou-se também o método bibliográfico, com a utilização de obras, revistas, artigos científicos e periódicos. 


\section{OS DIREITOS HUMANOS E A PROTEÇÃO INTERNACIONAL CONTRA A DISCRIMINAÇÃO ATENTATÓRIA}

Os direitos humanos são um produto da História, segundo uma concepção contemporânea oriunda da Declaração Universal de 1948 e reafirmada pela Declaração de Direitos Humanos de Viena de 1993. Conforme Norberto Bobbio (1992), eles nascem em certas circunstâncias, caracterizados por lutas em defesa de novas liberdades, de modo gradual e não todos de uma vez, nem de uma vez por todas.

Essa concepção é recente na História, uma vez que a Segunda Guerra Mundial foi o grande marco para que os direitos humanos fossem vistos sob o prisma da dignidade da pessoa humana. Diante das atrocidades cometidas aos seres humanos durante o Regime do Terceiro Reich, na Alemanha, especialmente para com os judeus, comunistas, homossexuais, ciganos, pessoas com deficiência e demais minorias, os Estados criaram a ONU como uma verdadeira liga para a paz mundial (GORISCH, 2014). Nesse sentido, também leciona Flávia Piovesan:

\footnotetext{
É nesse cenário que se desenha o esforço de reconstrução dos direitos humanos, como paradigma e referencial ético a orientar a ordem internacional contemporânea. Ao cristalizar a lógica da barbárie, da destruição e da descartabilidade da pessoa humana, a Segunda Guerra Mundial simbolizou a ruptura com relação aos direitos humanos, significando o pós-Guerra a esperança de reconstrução desses mesmos direitos (2008, p. 4).
}

Destaca-se que, logo após a Segunda Guerra Mundial, um tribunal se reuniu em Nuremberg, na Alemanha, entre os anos de 1945 e 1946, para julgar os crimes cometidos pelo nazismo durante a guerra, considerando-os crimes contra a humanidade. 
O totalitarismo concebido pelo regime nazista perseguiu, de forma violenta, os homossexuais, sendo uma das formas de barbárie a castração química realizada nos campos de concentração de forma experimental. Os homossexuais eram acusados, sobretudo, de ameaçar a evolução populacional da Alemanha. Segundo Clarindo Epaminondas de Sá Neto, a ação nazista "levou ao primeiro grande crime contra a diversidade sexual que se tem notícias, cujo evento ceifou a vida de pelo menos 15 mil homossexuais, os quais, na visão de Hitler, representavam a imagem de um comportamento degenerativo [...]” (2015, p. 30).

Nesse período, começa a ser traçado o sistema normativo internacional de proteção dos direitos humanos, dentro do Direito Internacional, bem como a elaboração de leis constitucionais dotadas de elevada carga axiológica, tendo como supedâneo e paradigma a dignidade da pessoa humana, "verdadeiro supraprincípio a orientar o constitucionalismo contemporâneo, nas esferas local, regional e global, dotando-lhes especial racionalidade, unidade e sentido" (PIOVESAN, 2008, p. 4).

O Direito Internacional, com relação aos Direitos Humanos, criou uma dicotomia entre, de um lado, Direitos Civis e Políticos e, de outro, Direitos Econômicos, Sociais e Culturais. Assim, a Declaração Universal dos Direitos Humanos, de 1948, juntamente com o Pacto Internacional dos Direitos Civis e Políticos e com o Pacto Internacional de Direitos Econômicos, Sociais e Culturais, formam a Carta Internacional dos Direitos Humanos.

A Declaração de 1948, uma visão contemporânea dos Direitos Humanos, tem como signo a universalidade e a indivisibilidade desses direitos. Com relação à universalidade, é o fato de que o requisito único para ser titular desses direitos é a condição de pessoa, de ser humano; já a indivisibilidade declara que a "garantia dos direitos civis e políticos é 
condição para a observância dos direitos sociais, econômicos e culturais e vice-versa. Quando um deles é violado, os demais também são" (PIOVESAN, 2008, p. 5).

Nesse sentido, os direitos humanos propriamente ditos são direitos de todos os homens, simplesmente por serem pessoas, sem nenhuma distinção de raça, cor, orientação sexual, religião, língua, nacionalidade ou qualquer outra forma. Os direitos humanos visam à proteção das pessoas contra ações que interferem em suas liberdades ou violem sua dignidade humana.

Ressalta-se que ao lado do sistema global - sistema internacional de proteção dos direitos humanos por intermédio de pactos e convenções (ONU) - surgem também os sistemas regionais de proteção dos direitos humanos, sobretudo na Europa, América e África. Tais sistemas, global e regional, são complementares no sentido de proporcionarem uma maior efetividade dos direitos fundamentais. Preleciona Dimitri Sales:

Declaração Universal dos Direitos Humanos de 1948 representou o principal instrumento legal do pós-guerra, delineando preceitos e princípios jurídicos que fundamentaram a emergência do direito internacional dos direitos humanos. Com a criação da Organização das Nações Unidas e, posteriormente, com o surgimento de sistemas regionais de defesa dos direitos humanos, consagrou-se a sistemática jurídica internacional de proteção de direitos e garantias da pessoa. Passe-se ao reconhecimento universal e à proteção internacional dos direitos humanos. Desde então, são inúmeros os avanços da diplomacia internacional no sentido de reconhecer e afirmar direitos que assegurem o respeito à dignidade da pessoa humana (2010).

A ONU, desde a sua criação em 1945, vem editando formas de proteção internacional contra a discriminação atentatória. Em 1965, a Convenção sobre a Eliminação de todas as formas de Discriminação Racial, 
em 1979, elaborou a Convenção sobre a Eliminação de todas as formas de Discriminação contra a Mulher e, em 1990, a Convenção sobre os Direitos da Criança.

A ONU, todavia, ainda não havia tratado sobre o tema da orientação sexual e da identidade de gênero. Somente após considerar, em 1994, que as leis da Austrália violavam os direitos humanos LGBTs, ante o julgamento do caso Toonen v. Austrália, que criminalizavam a prática homossexual, foi que o "Comitê Internacional de Direitos Civis e Políticos (ICCPR), vinculado ao Conselho de Direitos Humanos declarou que leis que violem os direitos LGBT violam as leis de Direitos Humanos” (GORISCH, 2014, p. 41).

Ademais, em 14 de junho de 2011, a ONU editou uma Resolução no Conselho de Direitos Humanos, apresentada pelo Brasil e África do Sul, denominada de "Direitos Humanos, orientação sexual e identidade de gênero”. Essa foi a primeira Resolução de defesa dos direitos das pessoas LGBTs a ser aprovada pela ONU.

Nessa Resolução, entre as importantes ações está a solicitação de um estudo sobre leis discriminatórias e atos praticados com motivação homofóbica, posto que esse levantamento permitirá vislumbrar como a lei internacional de direitos humanos será útil para o fim desta violência. Assim leciona a advogada e professora Patricia Gorisch sobre o conceito de Resolução:

[...] um dos instrumentos no Direito Internacional, Resolução é um ato que emana, em princípio, de um órgão intergovernamental e que propõe aos seus destinatários um determinado comportamento, sendo desprovido de força obrigatória. O art. 189 do Tratado que cria a Comunidade Europeia estipula expressamente que as recomendações e pareceres do Conselho e da Comissão não se vinculam (2014, p. 45). 
Destaca-se que uma Resolução internacional somente se torna obrigatória após a aceitação expressa ou tácita do Estado-membro. $\mathrm{Na}$ Resolução em comento, sobre os Direitos Humanos, a orientação sexual e a identidade de gênero, como visto alhures, o Brasil foi um dos apresentantes originais. Dessa forma, como a Resolução partiu do próprio Brasil, tem aceitação tácita do Estado brasileiro, nos termos da prevalência dos Direitos Humanos, no artigo $4^{\circ}$, inciso II, da Constituição Federal. Assim, compete ao Brasil reconhecer a Resolução e instituí-la por meio de mecanismos protetivos, como políticas públicas de proteção às pessoas LGBTs.

Com efeito, a Constituição Federal do Brasil, de 1988, dispõe em seu artigo $4^{\circ}$, inciso II, que o Brasil, em suas relações internacionais, é regido pela prevalência dos direitos humanos. Também no artigo $5^{\circ}, \S^{\circ}$, a Constituição determina que os direitos e garantias nela expressos não excluirão outros advindos de tratados internacionais de que o Brasil seja parte; ainda no $\S 3^{\circ}$, acrescenta que os tratados e convenções internacionais sobre direitos humanos aprovados em cada casa do Congresso Nacional, em votação de dois turnos, por três quintos dos votos, terão status de norma constitucional equivalente.

\section{DISTINÇÃO ENTRE DIREITOS HUMANOS, DIREITOS FUNDAMENTAIS E DIREITOS DA PERSONALIDADE}

A doutrina comumente utiliza os direitos humanos e os direitos fundamentais como sinônimos e os direitos da personalidade como espécie destes. Nem todos os direitos da personalidade, todavia, são direitos fundamentais e vice-versa. A título de exemplo, a autonomia privada é direito da personalidade, porém não é direito fundamental. De outro lado, o lazer (turismo) é um direito fundamental, porém não é um direito da personalidade. 
Além disso, os direitos fundamentais nascem em oposição ao Estado absolutista (o Estado não se sujeita às leis) e em consonância com o Estado de Direito - império da lei no qual governante e governados são submetidos às leis -; já os direitos da personalidade são inatos ao ser humano.

Os direitos humanos guardam uma relação direta com os documentos de Direito Internacional, uma vez que são reconhecidos a todo ser humano pela ordem internacional, independentemente de sua origem nacional ou de positivação na esfera constitucional, sendo, portanto, para todos os povos e todos os tempos em razão de seu caráter supranacional.

De outro lado, os direitos fundamentais são aquelas prerrogativas reconhecidas e positivadas em capítulos das constituições dos Estados modernos. Nas palavras de Clarindo Epaminondas de Sá Neto:

[direitos fundamentais] são aquelas prerrogativas que o constituinte achou por bem fazer presente no rol dos direitos entendidos como os mais importantes, para o respectivo momento histórico e político. Constituem-se, quase sempre. Em cláusulas pétreas, claro, quando se estar a falar em constituições rígidas, nas quais esses direitos integram o núcleo imodificável do texto constitucional, possuindo tais normas eficácia de caráter pleno e imediato, cujas garantias para o respectivo exercício dos direitos também encontram-se previstas no mesmo texto, revestindo-se dos mesmos caracteres mencionados (2015, p. 35).

Após a Emenda Constitucional $\mathrm{n}^{\mathrm{o}}$ 45, de 2004, os tratados de direitos humanos, nos termos do artigo $5^{\circ}$, $§ 3^{\circ}$, da Constituição Federal, aprovados em cada Casa do Congresso Nacional, em dois turnos, por 3/5 dos votos dos respectivos membros, serão equivalentes às emendas constitucionais e terão status constitucional de direito fundamental. 
Ainda, os tratados de direitos humanos que não receberem a aprovação no Congresso Nacional, mas forem ratificados e internalizados ao ordenamento jurídico brasileiro, terão status de norma supralegal, ou seja, abaixo da Constituição Federal e acima das leis ordinárias. Um exemplo é o Pacto de São José da Costa Rica, o qual tem status supralegal.

De outro lado, os direitos da personalidade são direitos inerentes à pessoa humana, isto é, eles nascem e morrem com a pessoa; o titular do direito da personalidade, no entanto, pode renunciar ao seu exercício, não podendo renunciar somente ao direito em si. São direitos ligados à noção de individualidade, liberdade e dignidade; são inatos à pessoa humana. "O direito da personalidade é um direito subjetivo, de caráter não patrimonial, que visa, na verdade, tutelar a própria pessoa humana, a sua dignidade $\mathrm{e}$ integridade" (CARDIN; BENVENUTO, 2013).

Horácio Monteschio preleciona que "os direitos da personalidade possuem estrito relacionamento com o direito natural, por assim dizer, passam a representar o mínimo necessário do conteúdo da própria personalidade” (2015, p. 85). Nesse sentido, Roxana Cardoso Brasileiro Borges descreve a vinculação dos direitos da personalidade com o direito natural:

Os jusnaturalistas concebem os direitos de personalidade como direitos naturais. Para alguns, os direitos de personalidade são direitos naturais porque foram estabelecidos por uma vontade divina que é revelada aos homens, cabendo a esses reconhecer essa razão divina e organizar a sociedade conforme o modelo revelado. Outros concebem os direitos de personalidade como direitos naturais porque aqueles derivam de uma ordem natural ou de uma lei que deriva da natureza e, sendo o ser humano um componente desta, deve, também, submeter-se a essa lei natural. Há ainda jusnaturalistas para os quais os direitos de personalidade derivam da razão, algo inerente ao homem (2007, p. 22-23).

A personalidade ou a capacidade jurídica, no entendimento de Adriano de Cupis, é uma qualidade jurídica e, como tal, "é um produto do direito positivo, e não uma realidade que este encontre já constituída 
na natureza e que se limite a registrar tal como a encontra” (2008, p. 19). Para Cupis, portanto, os direitos da personalidade não precedem do direito natural. Acrescenta, ainda, que são direitos essenciais, sem os quais a pessoa não existiria como pessoa:

[...] existem certos direitos sem os quais a personalidade restaria uma susceptibilidade completamente irrealizada, privada de todo o valor concreto: direitos sem os quais todos os outros direitos subjetivos perderiam todo o interesse para o indivíduo - o que equivale a dizer que, se eles não existissem, a pessoa não existiria como tal. São esses os chamados "direitos essenciais", com os quais se identificam precisamente os direitos da personalidade. [...] quando os direitos se revestem da referida essencialidade, não só tomam o lugar próprio no sistema do ordenamento positivo, mas adquirem, além disso, uma disciplina adequada e apta a assegurar-lhes proeminência relativamente a todos os outros direitos da pessoa a que se referem. [...] Por consequência, não é possível denominar os direitos da personalidade como "direitos inatos" entendidos no sentido, de direitos relativos, por natureza, à pessoa (2008, p. 24-25).

Destaca-se que alguns direitos da personalidade violados diante de condutas homofóbicas estão elencados na Constituição Federal, no artigo $5^{\circ}$, inciso X: "são invioláveis a intimidade, a vida privada, a honra e a imagem das pessoas, assegurado o direito a indenização pelo dano material ou moral decorrente de sua violação”. Já no Código Civil, os direitos da personalidade estão dispostos dos artigos 11 a 21 .

Com supedâneo no princípio da dignidade da pessoa humana, Luiz Alberto David Araújo aduz que a busca pela felicidade é o desejo perene do homem e ele tem esse direito

[...] ao arrolar princípios como o do Estado Democrático, o da dignidade da pessoa humana e o da necessidade de promoção do bem de todos, sem qualquer preconceito, o constituinte garantiu o direito à felicidade. Não o escreveu de forma expressa, mas deixou claro que 
o Estado, dentro do sistema nacional, tem a função de promover a felicidade, pois a dignidade, o bem de todos, pressupõe o direito de ser feliz (2000, p. 74).

Nesse diapasão, acrescenta que "ninguém pode conceber que um Estado que tenha como objetivo a promoção do bem de todos possa colaborar para a infelicidade do indivíduo. Portanto, a interpretação constitucional leva à busca da felicidade do indivíduo, não de sua infelicidade” (ARAÚJO, 2000, p. 74).

Desse modo, o direito à felicidade, ainda que não esteja expresso na nossa Lei Maior, é uma decorrência de outros princípios, como, por exemplo, a promoção do bem de todos sem qualquer forma de discriminação e, como tal, precisa ser garantido por todos, pelo Estado e pelas pessoas, posto que a busca pela felicidade é a meta de todo ser humano.

Hodiernamente, a violação dos direitos humanos das pessoas LGBTs é extrema, uma vez que por um lado muitos países não conseguem dar uma efetiva garantia de direitos e, por outro, mais de 70 países ainda criminalizam as condutas homossexuais, considerando-se que em alguns deles ainda se aplica a pena de morte como medida de repressão (OLIVA, 2016).

Por fim, é evidente que a discriminação atentatória das pessoas LGBTs viola os direitos da personalidade, como a honra, a vida privada e a liberdade de orientação sexual e identidade de gênero.

\section{PRINCÍPIOS CONSTITUCIONAIS CONTRA A DISCRIMINAÇÃO ATENTATÓRIA}

O Brasil adotou como princípio basilar, nos termos do artigo $1^{\circ}$, inciso III, da Constituição Federal, a Dignidade da Pessoa Humana. Para o último grande filósofo da era moderna, Immanuel Kant, o homem deve ser tratado como fim e não como meio e, em razão de seu valor, o homem tem dignidade e não preço. 
No reino dos fins tudo tem ou um preço ou uma dignidade. Quando uma coisa tem um preço, pode-se pôr em vez dela qualquer outra como equivalente; mas quando uma coisa está acima de todo o preço, e, portanto não permite equivalente, então tem ela dignidade (1974, p. 234).

Com o fim da Segunda Guerra Mundial, houve o surgimento da cultura pós-positivista, inserindo a filosofia moral no campo político, incluindo a dignidade da pessoa humana no campo jurídico mediante documentos internacionais e Constituições do mundo ocidental.

Ressalta-se que o princípio da dignidade da pessoa humana tem por objetivo promover o livre-desenvolvimento da pessoa, bem como tolher qualquer degradação ou tratamento desumano. O legislador ordinário tem a obrigação de elaborar normas de acordo com os mandados constitucionais de criminalização com o fim de evitar qualquer violação ao princípio basilar da dignidade da pessoa humana, o qual é núcleo dos direitos fundamentais.

Além do princípio da dignidade da pessoa humana, outros princípios que repudiam a discriminação atentatória e o preconceito sobre a orientação sexual e a identidade de gênero, são o princípio da não discriminação e o princípio da igualdade.

O princípio da não discriminação é corolário do princípio da igualdade e determina que o pleno exercício dos direitos e liberdades fundamentais pertence a todas as pessoas, ou seja, deve existir uma igualdade de tratamento a todo ser humano, independentemente de raça, nacionalidade, língua, etnia, cor, sexo, religião, condição social, etc.

A Constituição Federal, em seu artigo $5^{\circ}$, inciso XLI, dispõe que “a lei punirá qualquer discriminação atentatória dos direitos e liberdades fundamentais”, determinando, assim, a proibição da discriminação como bem jurídico a ser tutelado. 
De outro lado, o princípio da igualdade ou da isonomia está positivado na Constituição Federal em seu artigo 5, caput: “Todos são iguais perante a lei, sem distinção de qualquer natureza [...]”. Essa é a igualdade formal, porém não garante que todos tenham as mesmas oportunidades ou até mesmo uma participação social.

O princípio da igualdade formal, ou seja, a igualdade perante a lei, “exige que se reconheça em todos, independentemente da orientação homo ou heterossexual - a qualidade de sujeito de direito: isto significa, na prática, não identificá-lo com a pessoa heterossexual” (RIOS, 2002, p. 129).

Assim, diante do princípio da igualdade, existe a discussão no tocante à discriminação por orientação sexual perante duas formulações: a reivindicação dos direitos dos homossexuais e o direito à diferença. Tais formulações, contudo, não se encaixam na igualdade formal, uma vez que a equiparação entre os homossexuais e os heterossexuais culminaria no crescimento da discriminação, pois, dessa forma, partiria do pressuposto de que o heterossexual é o paradigma de sujeito de direito.

Também, com relação ao direito à diferença, no plano formal do princípio da igualdade tem-se que é visto de forma discriminatória em face da orientação sexual, considerando-se que quando se postula a diferença parte-se do pressuposto de que os heterossexuais são os iguais e os homossexuais são os diferentes.

Noutro giro, o princípio da igualdade material visa a tratar igualmente os iguais e desigualmente os desiguais, na medida de sua desigualdade. "Consequência disto, no domínio específico da orientação sexual, é a imposição de tratamento igual sempre que não se apresentarem razões suficientes para justificar a desigualdade de tratamento” (RIOS, 2002, p. 135). 
Uma das formas de garantia dessa igualdade material são as ações afirmativas, ou seja, políticas públicas que têm por objetivo combater discriminações de todo tipo, aumentando a participação das minorias no processo político, acesso à educação e emprego, corrigindo, assim, toda forma de desigualdade.

\section{DISCRIMINAÇÃO E PRECONCEITO HOMOFÓBICO}

As discriminações e os preconceitos existem, pois o ser humano é discriminador e preconceituoso. A discriminação está em todos os lugares e no cotidiano de todas as pessoas, uma vez que as pessoas são discriminadas pelo jeito de vestir, pela forma de falar, em razão de sua raça, sua cor, sua etnia, nacionalidade, orientação sexual, identidade de gênero, de uma doença infectocontagiosa, da pele tatuada; enfim, a discriminação pode ser velada ou incisiva.

Principalmente em tempos de tecnologias avançadas, os preconceitos e as discriminações ocorrem frequente e assiduamente por meio das redes sociais, pois, muitas vezes, as pessoas acreditam estar protegidas pelo anonimato de um perfil falso.

De acordo com a Convenção Internacional sobre a Eliminação de todas as Formas de Discriminação Racial, a Convenção sobre a Eliminação de todas as Formas de Discriminação contra a Mulher e a Convenção sobre os Direitos das Pessoas com Deficiência, todos incorporados ao ordenamento jurídico brasileiro, o conceito jurídico de discriminação é qualquer distinção, exclusão ou preferência que tenha o propósito ou o feito de anular ou prejudicar o reconhecimento, gozo ou exercício em pé de igualdade de direitos humanos e liberdades fundamentais nos campos econômico, social, cultural ou qualquer campo da vida pública. A esse con- 
ceito acrescenta-se a lista de critérios proibidos de discriminação, o que atenta para manifestações específicas de discriminação, como gênero, raça e etnia, religião, orientação sexual, deficiência e idade (RIOS, 2002, p. 139).

De outra forma, preconceito é uma opinião que se forma de outras pessoas antes mesmo de aprofundar relações ou de conhecê-las. Trata-se, portanto, de um julgamento prévio e superficial em relação às pessoas. O preconceito é moralmente condenável, já a discriminação está sujeita à punição por normas jurídicas. Muitas discriminações, todavia, são vistas como normatizações de uma sociedade, como, por exemplo, exigir boa aparência de um candidato para uma entrevista de emprego.

Com efeito, o juiz federal Roger Raupp Rios, membro do Centro Latino-Americano em Sexualidade e Direitos Humanos, traz à baila o seu entendimento na diferenciação entre preconceito e discriminação:

Por preconceito, designam-se as percepções mentais negativas em face de indivíduos e de grupos socialmente inferiorizados, bem como as representações sociais conectadas a tais percepções. Já o termo discriminação designa a materialização, no plano concreto das relações sociais, de atitudes arbitrárias, comissivas ou omissivas, relacionadas ao preconceito, que produzem violação de direitos dos indivíduos e dos grupos. O primeiro termo é utilizado largamente nos estudos acadêmicos, principalmente na psicologia e muitas vezes nas ciências sociais; 0 segundo, mais difundido no vocabulário jurídico (2009, p. 54).

Insta ressaltar que o preconceito velado ou não declarado existe e está presente no cotidiano de todas as pessoas, nas relações sociais ou em um programa de televisão. Tal preconceito aparece em situações como quando alguém diz: "Meu filho não será gay, ele terá uma boa educação", “Não tenho nada contra gays, ATÉ tenho amigos gays”, “Aquele negro é bom, é um negro de alma branca”. 
Assim, as pessoas, em seus íntimos, aceitam os padrões impostos pela sociedade e, com algumas atitudes, acabam por fomentar a estigmatização dessas minorias. Dessa forma, ser negro está relacionado com bandidagem e pobreza; ser gordo é não ter uma aparência física desejável; ser homossexual é ser promíscuo ou ser travesti é ser prostituta. $\mathrm{O}$ ideal é a prática do respeito e da tolerância para com todas as pessoas, sem distinção de sexo, raça, nacionalidade, religião, orientação sexual ou identidade de gênero.

Além disso, no ensinamento de Lourdes Bandeira e Analia Soria Batista (2016), o preconceito velado pode levar à violência:

É comum as pessoas terem algum tipo de preconceito não declarado, porque têm vergonha ou porque têm medo de serem criticadas ou até mesmo excluídas de certos grupos. Isso as leva a disfarçarem o preconceito, justificando racionalmente certos comportamentos que poderiam ser qualificados de discriminatórios. É nesse contexto sombrio que o preconceito discrimina e dá margem a práticas de violência, pois, seja pela sua onipotência ideológica, seja pela sua insolência mediática, acaba fomentando relações sociais hostis e violentas. $\mathrm{O}$ risco é que 0 preconceito pode ser suscetível e acabar se voltando contra seu portador, vítima ele/ela próprio/a do que nele não é digno de humanidade.

Dentre as discriminações atentatórias dos direitos e liberdades fundamentais, pode-se destacar o racismo, a xenofobia, o preconceito contra as pessoas com deficiência e contra as mulheres, entre tantas outras formas de discriminação. Nesse sentido, aqueles que julgam a superioridade da raça branca são designados pelo termo racismo, os que têm aversão ou antipatia aos estrangeiros praticam a xenofobia, os que têm ódio contra as mulheres cometem misoginia, etc.

Como exemplo paradigma de combate à discriminação em razão da diversidade sexual, tem-se a Argentina, que publicou a Lei de Identidade de Gênero, permitindo a essas pessoas uma visibilidade com “acesso 
à educação, à saúde e ao trabalho sem discriminação em razão de sua sexualidade, promovendo assim a diversidade entre todos os cidadãos e cidadãs” (SÁ NETO, 2015, p. 128).

No Brasil, as pessoas LGBTs ainda continuam na invisibilidade à espera de legislações que garantam uma igualdade material e que combatam à discriminação homofóbica e transfóbica, conforme as resoluções da ONU e da OEA, que reconhecem os direitos LGBTs como Direitos Humanos.

Essas ações afirmativas não necessariamente competem apenas ao Estado, posto que podem advir também da iniciativa privada, tal como acontece nos Estados Unidos, por exemplo. As discriminações positivas no Brasil quanto à responsabilidade de estabelecimento e aplicabilidade, entretanto, são quase uma exclusividade do Estado.

Conforme alguns doutrinadores, entre eles Celso Antonio Bandeira de Mello, a discriminação, para ser juridicamente válida, necessita ter por fim pessoas indeterminadas e indetermináveis, além de uma motivação lógico-racional, e estar conforme os valores constitucionalmente consagrados. Nessa linha de raciocínio, Paulo Roberto Iotti Vecchiatti acrescenta:

Por outro lado, é de se notar que a lição de Celso Antônio Bandeira de Mello deve ser complementada com a ponderação de Canotilho no sentido de que o princípio da isonomia não se resume à proibição do arbítrio (tão bem explicitada pelo primeiro), mas também à função social da igualdade, no sentido de ser a isonomia uma imposição constitucional relativa que, por isso, a caracteriza como uma forma de eliminação das desigualdades fáticas. Em outras palavras, ainda que a isonomia genericamente considerada não fundamente um dever absoluto de legislação, fundamenta um dever de legislação relativo, uma imposição constitucional acessória, uma exigência de atuação relativa, no sentido de que quando existirem pessoas essencialmente iguais àquelas que foram objeto de regulamentação legal, o princípio da igual- 
dade exigirá para estas uma disciplina legal igual à estabelecida para os casos já regulados, fundamentando um dever legislativo de atuação nesse sentido (2012, p. 198).

Por fim, as discriminações positivas ou discriminações juridicamente válidas por vezes contrariam a Constituição, mas nem por isso tornam inconstitucional uma lei que crie um tratamento diferenciado. Como exemplo, tem-se o Estatuto da Criança e do Adolescente e o Estatuto do Idoso, que criam regimes de proteção e diferenciação mais benéficos aos infantes e aos idosos mesmo diante da proibição de discriminação por idade elencado como objetivo da Constituição em seu artigo $3^{\circ}$, inciso IV.

\section{A HOMOFOBIA COMO VIOLAÇÃO DOS DIREITOS E LIBERDADES FUNDAMENTAIS}

A Constituição Federal, em seu artigo $5^{\circ}$, inciso XLI, dispõe que "a lei punirá qualquer discriminação atentatória dos direitos e liberdades fundamentais", determinando, dessa forma, a proibição da discriminação como bem jurídico. Assim, como o Direito não é estático e acompanha as evoluções sociais, históricas e culturais, é necessária a criação de normas jurídicas que assegurem a proteção da dignidade da pessoa humana, da igualdade e da vedação a tratamentos desumanos e degradantes, sem distinção de raça, cor, credo, idade, origem, identidade de gênero ou orientação sexual.

Conforme ensinamento do ministro Luiz Edson Fachin, o mais novo integrante do Supremo Tribunal Federal, existe um direito de cunho personalíssimo, o qual é o direito à orientação sexual, corolário da Constituição Federal, imprescindível para a construção de uma sociedade livre, justa e igualitária (2003, p. 121). 
A homofobia é a conduta hostil contra os homossexuais masculinos e femininos, uma modalidade de preconceito e discriminação motivada e direcionada aos homossexuais. A origem do termo homofobia se deu com o psicólogo norte-americano George Weinberg, em estudos realizados para definir o perfil da personalidade homofóbica no início da década de 1970, quando passou a utilizar a expressão "homosexualphobia” e, com isso, o termo alcançou os ares acadêmicos (RIOS, 2009, p. 60).

Daniel Borrillo, jurista ítalo-argentino e radicado na França, acrescenta: “[...] a invenção da palavra pertence a K.T. Smith que, em um artigo publicado em 1971, tentava analisar os traços da personalidade homofóbica; um ano depois, G. Weinberg definirá a homofobia como 'o receio de estar com um homossexual em um espaço fechado’ [...]” (2015, p. 21).

O termo homofobia comporta duas realidades: uma pessoal e outra social. A realidade pessoal tem uma dimensão subjetiva e se manifesta pela aversão, rejeição, ódio e desprezo pelos homossexuais. É denominada "homofobia irracional", pois provém de conflitos individuais. De outro lado, a realidade social tem cunho cultural, até mesmo político, e se revela em razão da heteronormatividade vigente, de forma que as pessoas até toleram ou simpatizam com os homossexuais, todavia não aceitam políticas públicas de igualdade para essa classe estigmatizada. É chamada de homofobia cognitiva, isto é, "ninguém rejeita os homossexuais; entretanto, ninguém fica chocado pelo fato de que eles não usufruam dos mesmos direitos reconhecidos aos heterossexuais" (BORRILLO, 2015, p. 24).

A origem da homofobia está estritamente relacionada com a concepção sexual do pensamento judaico-cristão. Também o mundo greco-romano, em razão da ordem patriarcal, sempre preconizou a superioridade masculina. Nessa linha de interpretação preconceituosa dos textos bíblicos, o cristianismo, mesmo na teologia moderna, sempre apregoou que a homossexualidade era um pecado contra a natureza capaz de comprometer os alicerces da sociedade (BORRILLO, 2015). 
Sobre a homofobia moderna, Roger Raupp Rios, citando Freud, Pocahy, Young-Bruehl e Borrillo, preconiza:

A discriminação homofóbica seria, portanto, sintoma que se cria a fim de evitar uma situação de perigo, cuja presença foi assinalada pela geração de angústia (FREUD, 1998: 56). Como refere Fernando Pocahy (2006), ao descrever a formulação psicológica desta dinâmica, da reação a este medo, geralmente paralisante e voltada para si em caráter de evitação, podem resultar atos de agressão visando suportá-lo. Daí a aplicação das abordagens psicológicas do fenômeno discriminatório à homofobia. Neste contexto, uma hipótese particularmente divulgada é a de que reações homofóbicas violentas provêm de sujeitos em grave conflito interno com suas próprias tendências homossexuais, resultantes da projeção de um sentimento insuportável de identificação inconsciente com a homossexualidade, donde a intolerância à homossexualidade. Não obstante a discussão sobre a posição freudiana diante da homossexualidade (YOUNG-BRUEHL, 1996: 13 9), o fato é que a "homofobia clínica", ao lado da "homofobia antropológica”, do stalinismo e do nazismo foram as principais ideologias que construíram a homofobia moderna, de caráter laico e não-teológico (BORRILLO, 2000) (2009, p. 61-62).

A homofobia, seja irracional ou cognitiva, ocorre em razão da heterossexualidade institucionalizada como norma, ainda que seja de modo implícito. Assim, o "binômio heterossexualidade/homossexualidade é critério distintivo para o reconhecimento da dignidade dos sujeitos e para distribuição dos benefícios sociais, políticos e econômicos” (RIOS, 2009, p. 63). Quando se pertence a um grupo vulnerável ou a uma minoria, os direitos e oportunidades são restritos ou até mesmo suprimidos.

Infelizmente, no Brasil, apesar das constantes evoluções com relação à garantia de direitos e liberdades fundamentais, ainda se vive sob a égide de uma ordem heterossexual, mesmo que de forma subjetiva. 
Assim, quando homossexuais, transexuais, lésbicas, travestis e outras pessoas desviam desse padrão de heteronormatividade, sofrem todo tipo de discriminações, hostilidades, violências físicas e morais.

\section{MINORIAS SEXUAIS E OS GRUPOS VULNERÁVEIS}

A sociedade é composta de pessoas ligadas por características físicas, culturais, sociais, econômicas e religiosas que, em virtude de sua vulnerabilidade social, não têm voz e necessitam de tutela especial dos direitos humanos. Assim, poder-se-ia conceituar democracia como a vontade da maioria, porém essa seria uma visão apenas quantitativa, uma vez que, qualitativamente, democracia é o regime das minorias, pois somente na democracia é que as minorias podem e devem ser ouvidas.

Nas palavras de Muniz Sodré, democracia é o palco das discussões sociais no qual as minorias têm voz ativa:

Eu disse primeiramente "voz”. É um significado subsumido, por exemplo, no modo como os alemães entendem maioridade e menoridade. Em Kant, maioridade é Mündigkeit, que implica literalmente a possibilidade de falar. Münd significa boca. Menoridade é Unmündigkeit, ou seja, a impossibilidade de falar. Menor é aquele que não tem acesso à fala plena, como o infans (2005, p. 12).

$\mathrm{Na}$ doutrina, as pessoas marginalizadas, sem voz e sem vez, ora são tratadas como grupos vulneráveis - que têm seus direitos humanos mais facilmente violados -, ora são referidas como minorias - consideradas inferiores e discriminadas pelos grupos majoritários.

Assim, na visão de Anjos Filho (2008), poder-se-ia classificar as minorias como espécie de grupos vulneráveis em sentido amplo. Dessa forma, grupos vulneráveis em sentido amplo seriam um gênero ao qual pertenceriam pessoas com deficiência, idosos, mulheres, homossexuais, 
favelados, crianças, minorias étnicas, religiosas e linguísticas, índios, dentre outros. Tais grupos vulneráveis, em sentido amplo, seriam divididos em duas espécies: minorias e grupos vulneráveis em sentido estrito.

O professor espanhol José Maria Contreras Mazarío (1997), citado por Marcelo dos Santos Bastos (2011), corrobora com o entendimento supramencionado de distinção entre minorias e grupos vulneráveis, no qual uma minoria é sempre um grupo vulnerável, ainda que o contrário não seja possível:

[minorias] son aquéllos que sufren una discriminación y se caracterizan por ser una sección no dominante de la población de dos Estados. Desde esta caracterización teórica, las minorías y os grupos vulnerables formarían una única y misma categoría. Sin embargo, a nuestro entender, una minoría es siempre un grupo vulnerable, entendiendo por tal um grupo no dominante o subordinado de la sociedade, pero no sucede lo mismo al contrario, esto es, no todo grupo vulnerable es uma minoría, ya que pueden no tener características éticas, religiosas o linguísticas, que sus miembros no se sientan unidos a dictos elementos distintivos como configuradores de su propria identidad o, en fin, que tengan ningún elemento de permanencia o de lealtad al Estado en que viven. Ello lleva a excluir del ámbito de proteción de la minoría a grupos tales como los refugiados, los asilados [e los extanjeros] (2011).

Ressalta-se que as minorias sempre estiveram presentes em toda sociedade e, no Brasil, de modo especial, por meio de uma cultura escravagista, uma vez que, desde a colonização portuguesa, utilizou-se a mão de obra indígena, depois a dos escravos negros e, no começo do século passado, a dos imigrantes. Essa questão de minorias, porém, passou a ser tratada pela Liga das Nações no período entre as duas grandes guerras mundiais, principalmente em razão das atrocidades ocorridas durante a Segunda Guerra Mundial, com o reconhecimento da dignidade da pessoa humana. 
Assim, diante da necessidade de um sistema internacional de proteção dos direitos humanos das minorias, com base na dignidade da pessoa humana, a qual é supedâneo de todo ordenamento jurídico pós-positivista, a ONU não conseguiu ainda chegar a um denominador comum que agrade a todos sobre uma definição clara de minorias.

No Brasil, a ministra do Supremo Tribunal Federal entende que o aspecto quantitativo não é fulcral na definição de minorias, posto que a proteção jurídica dos grupos minoritários deve levar em consideração o tratamento desigual e discriminatório dessas pessoas:

Não se toma minoria no sentido quantitativo, senão no de qualificação jurídica de grupos contemplados ou aceitos com um cabedal menor de direitos, efetivamente assegurados, que outros, que detém o poder (...) a minoria, na prática de direitos, nem sempre significa o menor número de pessoas. Antes, nesse caso, uma minoria pode bem compreender um contingente que supera em número (mas não na prática, no respeito, etc.) o que é tido por maioria (COELHO, 2016).

Em 1994, a ONU recomendou à Comissão de Direitos Humanos a criação de um grupo de trabalho no sentido de encontrar uma definição de minorias. Em 1997, Stanislav Chernichenko, membro da Subcomissão de Prevenção de Discriminação e de Proteção de Minorias das Nações Unidas, apresentou uma proposta sobre alguns requisitos norteadores das minorias, porém que não fosse uma obrigação legal, mas sim flexível e que servisse apenas como um guia.

Todas as propostas elaboradas pela ONU, juntamente com demais estudos elaborados por antropólogos, pela doutrina, jurisprudências e outros organismos internacionais, permitem determinar alguns elementos que caracterizam as minorias. Em geral, são apontados quatro elementos 
objetivos: o diferenciador, o quantitativo, a nacionalidade e a não dominância, bem como um elemento de natureza subjetiva: a solidariedade (ANJOS FILHO, 2008).

O elemento diferenciador - aquele que qualifica a minoria - exige que em cada pessoa do grupo minoritário haja uma determinada característica, de forma estável, que o distinga do grupo majoritário. Assim, a ONU considera para fins de proteção dos direitos humanos os elementos diferenciadores de etnia, religião e língua.

O elemento quantitativo parte do pressuposto de que os grupos numericamente majoritários não necessitam da proteção especial, de forma que nem todos os grupos numericamente inferiores devem ser necessariamente protegidos.

Já o elemento da nacionalidade sofreu algumas alterações, pois levava em consideração a condição de nacional ou cidadão como requisito para a minoria. O Comitê de Direitos Humanos, em interpretação do artigo 27 do Pacto Internacional sobre Direitos Civis e Políticos, reconhece os direitos a grupos minoritários que se encontram dentro dos limites territoriais, independentemente de serem cidadãos ou nacionais.

A não dominância consiste no fato de que o grupo minoritário, para ter direito à proteção especial, não pode estar em uma situação de domínio do processo político. Grupos que exercem o poder político, ainda que numericamente pequenos, estão em situação de destaque na sociedade.

Ainda, o elemento subjetivo da solidariedade significa uma vontade coletiva das pessoas pertencentes ao grupo de preservar as características que os distinguem das demais pessoas, ou seja, a preservação do elemento diferenciador.

De outro lado, Antonio Celso Baeta Minhoto conceitua minoria como "um segmento social, cultural, ou econômico vulnerável, incapaz de gerir e articular sua própria proteção e a de seus interesses, objeto de 
pré-conceituações e pré-qualificações de cunho moral em decorrência de seu distanciamento do padrão hegemônico [...]” e, em razão das características supra apresentadas, necessitam de uma proteção especial estatal (2013, p. 9).

Com relação às minorias sexuais, embora não se tenha uma conceituação precisa sobre a expressão, Paulo Roberto Iotti Vecchiatti assim a delimita:

Minorias sexuais são formadas por pessoas que são discriminadas por conta de sua orientação sexual, sua identidade de gênero ou por sua intersexualidade. Até hoje, as minorias sexuais sempre foram formadas por homossexuais, bissexuais, transexuais, travestis e intersexuais, ou seja, aqueles cuja orientação sexual não seja a heterossexual (homossexuais e bissexuais) e aqueles cuja identidade de gênero não coincida com o gênero socialmente atribuído ao sexo biológico (transexuais, travestis e intersexuais). Isso porque estes são os grupos de pessoas que são discriminadas unicamente por conta de sua sexualidade ou sua identidade de gênero, em virtude do heterossexismo social (2012, p. 37-38).

Ressalta-se que, até o final do século 20, as minorias sexuais sofriam uma discriminação mundial, pois somente a partir dos movimentos sociais em direito dos homossexuais, sobretudo desde a década de 70, nos Estados Unidos, essa categoria passou a ter um status de cidadania, ou seja, os homossexuais têm direito a ter direitos como pessoas e cidadãos.

Com a globalização, mediante o desenvolvimento tecnológico, as diferentes culturas iniciaram um estreitamento de laços sociais, o que favoreceu a discussão em torno dos movimentos sociais e o reconhecimento dos direitos das identidades étnicas, culturais, raciais, de gênero e sexuais. Em razão dessa pluralidade democrática, as minorias sexuais também iniciaram a busca pelo reconhecimento de seus direitos. 
Para um maior aprofundamento, Anjos Filho (2008) destaca alguns aspectos comuns tanto para minorias quanto para os grupos vulneráveis em sentido estrito: a) desnecessidade de os componentes dos grupos serem nacionais ou cidadãos do Estado em que se encontram; b) ambos são grupos não dominantes; c) incidência de vulnerabilidade.

Um exemplo de grupo vulnerável em sentido estrito e não composto por nacionais, mas que carece de proteção especial nos termos dos direitos humanos, é o de trabalhadores migrantes. Além disso, aqueles que têm o domínio político, ainda que sejam numericamente inferiores, não são enquadrados como vulneráveis, pois são elites político-econômicas. Antropologicamente, a condição de minoria decorre da relação de dominância e subordinação. Assim, a maioria é o grupo dominante, enquanto a minoria é o grupo dominado.

Ademais, Anjos Filho (2008) entende que, para fins de especial proteção dos Direitos Humanos, além da condição de não dominância, as minorias e os grupos vulneráveis em sentido estrito também devem estar em condição de vulnerabilidade. Com efeito, nem toda fragilidade é considerada uma vulnerabilidade, posto que as fragilidades são protegidas por mecanismos tradicionais, enquanto a vulnerabilidade implica necessidade de proteção especial de direitos humanos.

Nesta esteira, Anjos Filho (2008) aponta agora alguns aspectos distintivos entre minorias e grupos vulneráveis em sentido estrito: a) quanto aos elementos numéricos; b) quanto ao elemento diferenciador; c) quanto ao elemento solidariedade. As minorias, conforme projeto da Convenção de Proteção das Minorias elaborado pela Comissão Europeia da Democracia para o Direito, em 1991, são um grupo numericamente inferior ao resto da população de um Estado.

Já a exigência de inferioridade numérica não se aplica aos grupos vulneráveis em sentido estrito, pois estes podem ser numericamente majoritários. Um exemplo de necessidade de proteção especial para 
grupos vulneráveis numericamente superiores ocorreu no regime apartheid (regime de segregação racial adotado de 1948 a 1994 pelos sucessivos governos do Partido Nacional na África do Sul), no qual os direitos da maioria dos habitantes foram cerceados pelo governo formado pela minoria branca; assim, diante da vulnerabilidade, constituiu-se um grupo vulnerável em sentido estrito e não uma minoria (ANJOS FILHO, 2008).

Com relação ao elemento diferenciador, há distinções entre minorias e grupos vulneráveis em sentido estrito. De acordo com o Pacto Internacional de Direitos Civis e Políticos de 1966, em seu artigo 27, e a Declaração Sobre os Direitos das Pessoas Pertencentes a Minorias Nacionais ou Étnicas, Religiosas e Linguísticas de 1992, os direitos ali reconhecidos não abrangem todos os grupos vulneráveis, mas tão somente as minorias étnicas, religiosas e linguísticas, que, ao lado das minorias nacionais, são chamadas comumente pela doutrina de minorias históricas ou tradicionais (ANJOS FILHO, 2008).

Destaca-se que a cultura é o principal componente deste elemento diferenciador característico das minorias, sobretudo na minoria étnica, pois a cultura étnica se manifesta pelas tradições, língua e religião. Dessa forma, não é a natureza física (cor, idade, gênero) que qualifica uma minoria; ela [a natureza física] é um elemento diferenciador dos grupos vulneráveis em sentido estrito, bem como as opções derivadas da personalidade individual (homossexuais, travestis, simpatizantes de ideologias políticas) e aspectos socioeconômicos (pobres, favelados, presidiários, desempregados, sem-terra) (ANJOS FILHO, 2008).

Outra característica distintiva entre minorias e grupos vulneráveis em sentido estrito, é que nas minorias há necessariamente uma estabilidade do elemento diferenciador, já nos grupos vulneráveis, em sentido estrito, esse elemento pode ser permanente (negros, mulheres) ou temporário (presidiários, desempregados, refugiados) (ANJOS FILHO, 2008). 
Com relação à solidariedade, esta é de suma importância para a distinção entre minorias e grupos vulneráveis em sentido estrito. Para tanto, deve-se levar em consideração a proposta de definição de minorias elaborada pelas Nações Unidas por intermédio de Capotorti, Dêschenes e Chernichenko, que "expressamente exigem que o grupo em questão deseje, ao menos implicitamente, a manutenção de seus elementos diferenciadores" (ANJOS FILHO, 2008, p. 362).

Diante dessas explanações, as pessoas LGBTs não se enquadram como minorias, na visão mais restrita elaborada por Anjos Filho (2008), o qual leva em conta o elemento diferenciador da ONU, que reconhece os direitos apenas das minorias étnicas, religiosas e linguísticas, as quais são denominadas pela doutrina de minorias tradicionais. Com esse raciocínio, as pessoas LGBTs pertenceriam aos grupos vulneráveis em sentido estrito.

Em contraponto, diante da interpretação de Minhoto (2013), as pessoas LGBTs possuem as características das minorias, a saber: incapacidade de autoproteção; necessidade de especial proteção estatal; vulnerabilidade social; distanciamento do padrão hegemônico e opressão social.

Nesse sentido, é incontestável que a classe de pessoas pertencentes a essa minoria sexual denominada LGBT necessita de uma maior proteção estatal, com o escopo de promoção da igualdade material, com políticas públicas de discriminação positiva em razão da estigmatização social sofrida, pois não raro são vítimas de violências físicas e psicológicas.

\section{CONSIDERAÇÕES FINAIS}

Muitos avanços foram conquistados pelas mãos dos libertários movimentos LGBTs, como o reconhecimento de direitos humanos para os homossexuais e a despatologização da homossexualidade em 1974, com a supressão da homossexualidade da lista de doenças mentais. 
Em 1993, a Organização Mundial da Saúde, na edição do CID 10, deixou de utilizar o termo homossexualidade e incluiu a categoria de orientação sexual, observando, todavia, que a orientação sexual de forma isolada não deve ser considerada um transtorno. Nessa linha, o Conselho Federal de Psicologia no Brasil, em 1999, afirmou que a homossexualidade não é uma doença, desvio psicológico ou perversão.

Apesar de toda a evolução, dados estatísticos mostram que a violência e a discriminação homofóbica são crescentes no Brasil. A comunidade LGBT luta e reivindica maior proteção estatal por meio de políticas públicas de discriminação positiva, em razão das condutas motivadas por preconceito e discriminação contra os homossexuais, mas o seu grito, o seu desespero, não tem atingido o Congresso Nacional, que se mantém inerte com relação à violência exercida sobre essa minoria sexual.

É mister a punição das discriminações atentatórias por orientação sexual - aquela cometida contra homossexuais, bissexuais ou heterossexuais -, bem como das discriminações por identidade de gênero - aquela cometida contra travestis, transexuais e transgêneros.

Essa discriminação viola, ainda, os direitos da personalidade, sobretudo o direito à honra (tanto no viés objetivo quanto no subjetivo), o direito à vida privada e o direito à liberdade.

Todas as pessoas têm direito à liberdade, o qual é um direito subjetivo que autoriza a pessoa a fazer tudo o que ela desejar, desde que não seja contrário à lei, ou seja, as pessoas não podem sofrer limitações em sua liberdade, exceto se tal liberdade for contrária ao ordenamento jurídico.

Ademais, todos têm também o direito à felicidade ou direito à busca pela felicidade. Mesmo que este direito não esteja explícito constitucionalmente, não se pode olvidar que é um direito fundamental, pois o Estado tem o dever de promover o bem de todos, com igualdade, sem discriminação, com supedâneo no princípio da dignidade da pessoa humana. 
Por fim, ainda que alguns argumentem que a punição estatal não seja a melhor solução para a vedação de condutas discriminatórias, uma vez que poderia se utilizar do controle social difuso ou informal para realizar um trabalho preventivo de diálogo e orientação nas escolas, nas famílias e demais ambientes favoráveis para a aplicabilidade da discussão, diante do cenário atual de violência, ódio e intolerância, conclui-se que seja necessária uma proteção estatal com o fito de punição contra a discriminação e o preconceito motivado por questões homofóbicas.

\section{REFERÊNCIAS}

ANJOS FILHO, Robério N. dos. Minorias e grupos vulneráveis: uma proposta de distinção. In: ROCHA, J. C. de Carvalho; HENRIQUES FILHO, T. H. P.; CAZZETA, U. (Coord.). Direitos humanos: desafios humanitários contemporâneos: 10 anos do Estatuto dos Refugiados (Lei n. 9.474, de 22 de julho de 1997). Belo Horizonte: Del Rey, 2008.

ARAÚJO, Luiz A. D. A proteção constitucional do transexual. São Paulo: Saraiva, 2000.

BANDEIRA, Lourdes; BATISTA, Analia S. Preconceito e discriminação como expressões de violência. Disponível em: <http://www.scielo.br/pdf/ref/ v10n1/11632.pdf>. Acesso em: 22 nov. 2016.

BOBBIO, Norberto. A era dos direitos. Trad. Carlos Nélson Coutinho. Rio de Janeiro: Campus, 1992.

BORGES, Roxana C. B. Direitos de personalidade e autonomia privada. 2. ed. rev. São Paulo: Saraiva, 2007.

BORRILLO, Daniel. Homofobia: história e crítica de um preconceito. Belo Horizonte: Autêntica, 2015.

BASTOS, Marcelo dos Santos. Da inclusão das minorias e dos grupos vulneráveis: uma vertente eficaz e necessária para a continuidade da ordem jurídica constitucional. Revista Brasileira de Direito Constitucional-RBDC, n. 18. jul./ 
dez. 2011. Disponível em: <http://www.esdc.com.br/RBDC/RBDC-18/RBDC18-039-Artigo_Marcelo_dos_Santos_Bastos_(Da_Inclusao_das_Minorias_e_ dos_Grupos_Vulneraveis).pdf.>. Acesso em: 3 ago. 2016.

CARDIN, Valéria S. G.; BENVENUTO, Fernanda M. Do reconhecimento dos direitos dos transexuais como um dos direitos da personalidade. Revista Jurídica Cesumar - Mestrado, Maringá, PR: Unicesumar, v. 13, n. 1, 2013. Disponível em: <http://periodicos.unicesumar.edu.br/index.php/revjuridica/article/ view/2899/1896>. Acesso em: 9 ago. 2016.

COELHO, Fábio A. A idade mínima para a inscrição no regime geral de previdência social e os direitos dos indios. Disponível em: <http://www.publicadireito.com.br/conpedi/manaus/arquivos/anais/bh/fabio_alexandre_coelho. pdf.> Acesso em: 4 ago. 2016.

CUPIS, Adriano de. Os direitos da personalidade. Trad. Afonso Celso Furtado Rezende. São Paulo: Quorum, 2008.

FACHIN, Edson L. Direito de família: elementos críticos à luz do novo Código Civil brasileiro. 2. ed. rev. atual. Rio de Janeiro: Renovar, 2003.

GORISCH, Patricia. O reconhecimento dos direitos humanos LGBT: de Stonewall à ONU. Curitiba: Appris, 2014.

KANT, Immanuel. Fundamentação da metafísica dos costumes. São Paulo: Abril, 1974.

MAZARÍO, José Maria C. Las Naciones Unidas y la Protección de las Minorias Religiosas: de la tolerância a la interculturalidad. Tirant monografías. España: Universidad de Sevilla Pablo D’Olavide, 1997.

MINHOTO, Antonio Celso B. Da escravidão às cotas: a ação afirmativa e os negros no Brasil. Birigui, SP: Boreal, 2013.

MONTESCHIO, Horácio. A imagem como patrimônio: uma análise do conteúdo patrimonial do direito à imagem. Birigui, SP: Boreal, 2015. 
OLIVA, Thiago D. Minorias sexuais enquanto "grupo social" e o reconhecimento do status de refugiado no Brasil. Disponível em: <http://www.acnur.org/t3/ fileadmin/Documentos/portugues/eventos/Minorias_Sexuais_enquanto_ Grupo_Social.pdf?view=1>. Acesso em: 26 nov. 2016.

PIOVESAN, Flávia. Concepção contemporânea de direitos humanos: desafios e perspectivas. In: ROCHA, J. C. de Carvalho; HENRIQUES FILHO, T. H. P.; CAZZETA, U. (Coord.). Direitos humanos: desafios humanitários contemporâneos: 10 anos do Estatuto dos Refugiados (Lei n. 9.474, de 22 de julho de 1997). Belo Horizonte: Del Rey, 2008.

RIOS, Roger R. O princípio da igualdade e a discriminação por orientação sexual: a homossexualidade no direito brasileiro e norte-americano. São Paulo: Revista dos Tribunais, 2002.

Homofobia na perspectiva dos Direitos Humanos e no contexto dos estudos sobre preconceito e discriminação. In: JUNQUEIRA, Rogério D. (Org.). Diversidade sexual na educação: problematizações sobre a homofobia nas escolas. Brasília: Ministério da Educação; Secretaria de Educação Continuada; Alfabetização e Diversidade; Unesco, 2009.

RIOS, Roger R.; SILVA, Rodrigo da. Discriminação múltipla e discriminação interseccional: aportes do feminismo negro e do direito da antidiscriminação. Disponível em: <http://www.scielo.br/pdf/rbcpol/n16/0103-3352-rbcpol-16-00011.pdf>. Acesso em: 15 jun. 2016.

SÁ NETO. Clarindo E. de. Diversidade sexual: direito humano ou direito a ser humano? Erechim, RS: Deviant, 2015.

SALES, Dimitri N. Direito à visibilidade: direito humano da população GLBTT. 2010. Disponível em: <http://www.oabsp.org.br/comissoes2010/diversidade-sexual-combate-homofobia/artigos/Direito\%20a\%20Visibilidade-Direito\%20 Humano\%20da\%20Populacao\%20GLBTT.pdf×. Acesso em: 19 nov. 2016.

SODRÉ, Muniz. Por um conceito de minoria. In: PAIVA, Raquel; BARBALHO, Alexandre (Org.). Comunicação e cultura das minorias. São Paulo: Paulus, 2005. 
SIQUEIRA, Dirceu Pereira; PAIVA, Caroline Zanetti. A utilização da mediação como forma de efetivação ao acesso à justiça e o princípio da dignidade da pessoa humana. Revista Eletrônica do Curso de Direito da UFSM, v. 11, n. 1, 2016. Disponível em: <https://periodicos.ufsm.br/revistadireito/article/ view/20505/pdf\#.WMmI_m_yt0x>. Acesso em: 7 jan. 2017.

SIQUEIRA, Dirceu Pereira; RUIZ, Ivan Aparecido. Acesso à justiça e os direitos da personalidade. Birigui: Boreal, 2015.

SIQUEIRA, Dirceu Pereira; OLIVEIRA, Flavio Luis de. Acesso à justiça e concretização de direitos. Birigui: Boreal, 2014.

SIQUEIRA, Dirceu Pereira; FERRARI, Caroline Clariano. O direito à informação como direito fundamental ao estado democrático. Revista Direitos Sociais e Políticas Públicas - Unifafibe, v. 4, n. 2, 2016.

VECCHIATTI, Paulo Roberto I. Minorias sexuais e ações afirmativas. In: VIEIRA, Tereza R. (Org.). Minorias sexuais: direitos e preconceitos. Brasília, DF: Consulex, 2012. 